\title{
Perspective of the "Weaknesses" of English Education in Ethnic Areas under Reinforcement Theory
}

\author{
Liming Zhang \\ Yancheng Institute of Industry Technology, Yancheng, 224001, China
}

\begin{abstract}
Keywords: Reinforcement theory; Ethnic area; English education; Reform
\end{abstract}
\begin{abstract}
The ethnic area generally refers to the area inhabited by minorities. Our country is a multi-national country with a lot of ethnic areas. Since the ethnic areas all have their own languages and words and their geographic locations are relatively faraway, their internal teaching development maybe cannot fit the development of modern education; furthermore, there is a huge influence on the education of ethnic area under the teaching pattern of reinforcement theory. This paper mainly studies and discusses the "weaknesses" (namely, shortcomings or loopholes) of English education in ethnic areas .
\end{abstract}

\section{Introduction}

We are a country with the joint development of multiple nationalities. Over recent years, with the social, economic, scientific and technological development of our country, the social development's demand for talents has been more targeted. In order to adapt to the social development and need, the country have been making reforms for new courses continuously to promote the education and teaching to be carried out effectively. The reinforcement theory, which is a method to reinforce knowledge learning and memorizing through reinforcement measures, has all-important significance for practical teaching. At this stage, the development of English teaching becomes increasingly important, directly affecting the educational development of our country. However, some ethnic areas still lack English education, which goes against to the development of our country's educational business. Therefore, this paper will discuss the phenomenon that there are defects in English education in ethnic areas under the reinforcement theory and solutions will be put forward accordingly.

\section{Content of reinforcement theory}

The reinforcement theory, which is reflected as reinforced learning theory and reinforced management theory in practical teaching, is a theory originally put forward by Skinner, the American psychologist, through the phenomenon that the white rate or pigeon acquires food from the uniquely-designed box, and is also called the theory of amendment for operant conditional reflex ${ }^{[1]}$. The conditioned reflex, which was put forward by Pavlov, principally states that a human body under a long-term stimulation will have automatic response to the stimulation. In case of a second stimulus, the human body will have corresponding morphologic expression to the stimulus. The reinforcement theory is the theoretical development based on conditioned reflex and emphasizes more about the influence of reinforcement effect. The reinforcement effect falls into positive reinforcement, which generates positive results, and negative reinforcement, which results in negative results ${ }^{[2]}$. The human body's behaviors will be amended through such results.

Such reinforcement theory is applied in teaching mainly to reinforce learning and management. The reinforced learning theory, which principally reinforces the learning content, will looks for a reinforcer for the students through some formulas to help the students to memorize the knowledge more deeply. In the course of study, Skinner emphasizes that learning needs to be carried out progressively based on certain feedback rules and the problems caught in the course of study shall be subdivided into smalls ones to be solved. He also thinks the key to the existence of learning is reinforcement; namely, if a student doesn't reinforce the knowledge after learning it, he may forget 
all the knowledge, which goes against his learning [3]. Such way of reinforced learning has an important influence on the development of education and teaching of our country. The reinforced management theory, which also reinforces the management content, refers to a workaround for increasing the frequency of occurrence of some previous actions of people. Skinner thinks that if a response can be reinforced timely after its occurrence, the occurrence rate of such response can be reinforced [4]; besides, this reinforcement will be affected by the environment, so it must be coordinated with the environment to jointly control the reflex action. It gives expressions in education and teaching to that the school or class builds an environment available for effective organization by using reinforcement measures to manage the students, to adapt the students' behaviors to the management of school or class and to promote the developing of learning. Two types of extreme reinforcement rent, namely the positive and negative reinforcement, appear in the education and teaching management. The positive reinforcement will reinforce the students' behaviors while the negative reinforcement is punitive to some degree [5]. To reduce the occurrences of such behaviors will influence the developing of education and teaching and the learning growth of students to some degree.

The reinforcement theory held an important position in the past education and teaching and still has significant influences on education and teaching at present. How to effectively utilize such reinforcement theory is crucial for the development of education and teaching. With the economic construction of our country as well as the development of science and technology, our country increasingly emphasizes the cultivation of talents and has made abundant reforms to the educational system. Such reforms caused the generation of the educational pattern of reinforcement theory. It is required to adjust measures to local conditions and to difference persons and to adopt varied patterns of reinforcement to promote the development of education.

\section{Problems in English education in ethnic areas under reinforcement theory}

At the present stage, English education is the key point of our country's development. With the rising of the international influence and international status of our country, the development of our country will gradually be world-orientated. As English is the all-purpose language among countries, to cultivate the talents who adapt to the development of modern society, it is necessary to strengthen both the students' English learning ability and the effect of English education. Skinner conducted rather complete experimental process so the experimental result is reliable. As shown in his research result, the reinforcement theory plays a role in actively promoting the development of education and teaching and has theoretical and practical significance in reality ${ }^{[6]}$; for this reason, such reinforcement theory has been widely used in practical teaching and develops ceaselessly with the development of the traditional education and teaching pattern. Since our country is a country with multiple nationalities, there are a lot of ethnic areas in our country. Because all of these nationalities have their own unique languages and, meanwhile, they are located in rather faraway areas, there are a lot of problems in carrying out English education in these ethnic areas. Although our country continuously propagandize the importance of English education in extensive areas and carries out English teaching nationwide, but these problems still haven't been practically solved. The existence of these problems hinders the development of English education in our country. Under such reinforcement theory, basically, there are the following four problems in English education in the ethnic areas.

\section{Cultural barrier caused by the unique languages in the ethnic areas}

There are fifty six nationalities in our country and each of them has their own language and culture. Furthermore, our country carries out the policy of regional autonomy of minority nationalities, encouraging them to develop their own cultural characteristics in the ethnic areas. Because English is a foreign language, it is difficult to learn it for the students who are used to using their local languages. Besides, with their own language customs and local language cultures, the students in the ethnic areas cannot quickly understand the grammar results in English teaching, which causes the phenomenon of cultural barrier ${ }^{[7]}$. For example, when English education is carried out in some minority areas, it is 
difficult for the students to learn English due the fixed thinking pattern formed because the local students have their own languages and they speak their local languages in daily communications. In addition, the languages in some ethnic areas may influence the students' pronunciation. In south China, a lot of people cannot correctly pronounce "l” and " $n$ ". To carry out English education based on such national languages goes against the students' effective learning of English knowledge and thus the cultural barrier is caused.

\section{Poor English knowledge and cultural quality of teachers}

Due to the relatively faraway geographic location, inconvenient transportation, rather backward economic development and blocking educational environment in many ethnic areas, there are few bilingual teachers with high cultural quality; so it resulted in the phenomenon that the teachers can communicate well with their students and can carry out the teaching of other subjects, but they have some language barriers. If the English teachers in the ethnic areas are outsiders with solid basic English knowledge but fails to understand the local languages well, they will still suffer the difficulty in English teaching. Therefore, there are no corresponding bilingual teachers in such ethnic areas. At the same time, because of the blocking educational environment in the ethnic areas and poor cultural quality of local English teachers, the teachers fail to combine the teaching content with the development of times while carrying out English teaching, resulting in power English ability of the students in the ethnic areas.

\section{No attention paid to the learning characteristics of students in the ethnic areas}

Just like the development of Chinese history, the development of ethnic areas also went through the historical accumulation for a long time to form their unique ethnic characteristics. Since the students together with their parents here have lived in such cultural environments of the ethnic areas at birth, they have formed their unique thinking modes, the so-called second nature. The long-standing habits bestowed the students with their fixed learning characteristics. To carry out English education in the ethnic areas without paying attention to the learning characteristics of the local students will certainly cause difficulties in English learning and teaching ${ }^{[8]}$. For this reason, while carrying out English teaching in the ethnic areas, the teachers need to emphasize the students' learning characteristics in the ethnic areas and to use the teaching patterns, which fit for the development of the ethnic areas, are acceptable for the students in the ethnic areas, are easy to be understood and applied by the students in the ethnic areas, reinforce the students' English learning and enhance the effect of English education in the ethnic areas. Without paying attention to the students' learning characteristics in the ethnic areas, we cannot develop the English teaching in the ethnic areas, which is to the disadvantage of the establishment of the students' English knowledge system.

\section{Incomplete basic educational facilities and no corresponding teaching resources}

English teaching develops pretty fast in our country. According to the provisions of our past policies, a school must set the English language teaching in grade one of junior high school. However, with the increasing rising of the entire strength of our country as well as the development of the international economic globalization, the quality of English teaching has more and more huge influence on the development of our country, so our country pays more attention to the development English education from place to place and takes English as a foundation course and English teaching has been set for the students in the first grade of primary school. It thus can be seen that English education develops rather fast in our country, largely influencing the international development of our country. Therefore, it is of practical significance to strengthen the English education in the ethnic areas. But the geographic limitation and economic limitation of the ethnic areas cause incomplete basic educational facilities in such areas, which exerts negative influences on the development of English education. For example, to learn some English words, the students' learning effect can be strengthened through animations or games; but some ethnic areas are limited by many factors, restricting the development of English education. Meanwhile, there are neither sufficient teaching resources nor corresponding textbooks with new teaching reforms, so the students cannot get their own English knowledge system updated. 


\section{Development countermeasures for English education in the ethnic areas}

To resolve the problem arisen in English education in the ethnic areas under the reinforcement theory, it is required to take corresponding reinforcement measures according to the practical development of the ethnic areas. There are basically three countermeasures below to promote the effective implementation and development of English teaching in the ethnic areas.

\section{Strengthen the concept of English learning in the ethnic areas}

Although their unique ethnic languages cause some English learning barriers in the ethnic areas, English education is a significant impetus for the social development at this stage; the society also needs abundant English talents. Therefore, it is required to strengthen the concept of English learning in the ethnic areas, to overcome the barriers among languages and to invest more energies and time to strengthen the development of English education.

\section{The state implements corresponding polices for teaching support}

In view of the geographic and economic limitations and lack of excellent bilingual teachers in the ethnic areas, the country needs to implement corresponding polices for teaching support, such as organizing English education in the mountainous areas, continuously improving and developing the policy of development of the west regions, so as to make more excellent talents to devote themselves to the English teaching business in the ethnic areas and to promote the development of the national English educational level.

The state carries out fiscal appropriations to the ethnic areas to perfect the teaching facilities and resources in the ethnic areas

Both teaching facilities and teaching resources are the fundamentals of teaching. Lack of sufficient teaching facilities and resources in the ethnic areas resulted in the backward English educational level in the ethnic areas, which goes against the development of our country and also influences the learning of the local students. Thus, the state needs to offer financial supports for the development of English education in the ethnic areas, to improve the basic teaching facilities and resources in the ethnic areas, to emphasize English education in the ethnic areas, to enhance our country's ability of English teaching fundamentally and to promote the integrated development of students in the ethnic areas so that they can adapt to the development and need of the modern society.

Although there are some problems in English teaching in the ethnic areas restricting the development of English education, we believe the English teaching in the ethnic areas will certainly conform to the development of times in the future as long as we continuously strengthen the concept of English education and the country ceaselessly offers economic supports.

\section{Conclusion}

To sum up, this paper mainly studies the problems in English education in the ethnic areas under the reinforcement theory. Since English education is the key point for educational development of our country at the present stage, to solve the problems in English education in the ethnic areas can promote the educational and economic development of our country and, meanwhile, can help us cultivate the talents who adapt to the development of the modern society.

\section{References}

[1] Chen Liqian. Curriculum Design for the English Education Majors in the Comprehensive Universities in the Ethnic Areas Should Highlight the Cultivating the Educational and Teaching Features of Elementary and Secondary School Teachers. Ethnic Education Research, 2013,(1):34-37.

[2] Yang Liping. Analysis on the Pattern of Talents Training in the Vocational English Education in the Ethnic Areas - Taking Lijiang, Yunnan for Example. Ethnic Education Research, 2012,23(3):60-63. 
[3] Kuang Yuhua. Discussion on Localization of English Education in Multiple Ethnic Frontier Regions. Modern Enterprise Education, 2013,(14):235-236,237.

[4] $\mathrm{Hu}$ Shuwei, Hu Xiao. Study on Countermeasures for Vocabulary Learning in Basic English Education in Hainan Ethnic Regions. Journal of Qiongzhou University, 2011,18(2):79-81,84.

[5] Chen Jing. Humble Opinions on Curriculum Design for the English Education Major of Higher Normal School in the Ethnic Areas. Journal of Aba Teachers College, 2012,29(1):105-107.

[6] Peng Qing. Local Cultural Input for English Education in the Local Universities in the Ethnic Areas. Journal of Hebei United University: Science and Technology Edition, 2012,12(1):55-58.

[7] Wu Shuwei, Hu Xiao. Problems and Countermeasures in the English Education for the Middle and Primary Schools in the Southern Hainan Ethnic Areas. Journal of Hainan Open University, 2011,12(2):82-86.

[8] Yao Yuhong. Positioning Analysis on the English Education Major for Universities in Hubei Ethnic Areas. Journal of Jiamusi Vocational College, 2015,(1):136-13. 